University of Nebraska - Lincoln

DigitalCommons@University of Nebraska - Lincoln

Repellency of Aqueous Solutions of Boric Acid and Polybor 3 to House Flies (Diptera: Muscidae)

Jerome Hogsette

USDA-ARS

Philip Koehler

USDA-ARS

Follow this and additional works at: https://digitalcommons.unl.edu/usdaarsfacpub

Part of the Agricultural Science Commons

Hogsette, Jerome and Koehler, Philip, "Repellency of Aqueous Solutions of Boric Acid and Polybor 3 to House Flies (Diptera: Muscidae)" (1994). Publications from USDA-ARS / UNL Faculty. 1007.

https://digitalcommons.unl.edu/usdaarsfacpub/1007

This Article is brought to you for free and open access by the U.S. Department of Agriculture: Agricultural Research Service, Lincoln, Nebraska at DigitalCommons@University of Nebraska - Lincoln. It has been accepted for inclusion in Publications from USDA-ARS / UNL Faculty by an authorized administrator of DigitalCommons@University of Nebraska - Lincoln. 


\title{
Repellency of Aqueous Solutions of Boric Acid and Polybor 3 to House Flies (Diptera: Muscidae)
}

\author{
JEROME A. HOGSETTE AND PHILIP G. KOEHLER ${ }^{1}$
}

Medical and Veterinary Entomology Research Laboratory, USDA-ARS, P.O. Box 14565, Gainesville, FL 32604

\begin{abstract}
J. Econ. Entomol. 87(4): 1033-1037 (1994)
ABSTRACT Mixed-sex 3- to 5-d-old adult house flies, Musca domestica (L.), were exposed in nonchoice, choice, and consumption tests to increasing levels of boric acid and polybor formulated in $10 \%$ sucrose to test for repellent effects. Results of nonchoice and choice tests suggested repellency to high levels of both borates. Consumption decreased at levels $>2.25 \%$ boric acid and $3.0 \%$ polybor, with approximate intake of 0.102 and $0.161 \mathrm{mg}$ of boron, respectively. Our results indicate that $2.25 \%$ boric acid and $3.0 \%$ polybor are optimal treatment levels.
\end{abstract}

KEY WORDS Musca domestica, boric acid, polybor 3

INSECTICIDAL PROPERTIES of boric acid and polybor 3 (Polybor, disodium octaborate tetrahydrate) have been evaluated with renewed interest to determine more accurately the potential of these borates for use against house fly, Musca domestica (L.), adults (Hogsette \& Koehler 1992, Mullens \& Rodriguez 1992). Boric acid was used routinely for fly control before the advent of chlorinated hydrocarbons and DDT, but it was used primarily as a larvicide (Bishopp 1939, Midgley et al. 1943, McGovran \& Piquett 1945). Sugarbase boric acid baits were tested against adults but were considered inferior to similar baits formulated with organophosphorus compounds (Langford et al. 1954).

In laboratory studies, Mullens \& Rodriguez (1992) demonstrated that polybor in dry sugar baits caused delayed adult mortality and reduced egg hatch when consumed by adult house flies. Also, sugar baits containing $>2 \%$ polybor were repellent to adult flies. Hogsette \& Koehler (1992) formulated boric acid and polybor in water and 10\% sucrose and found that mortality rates for adult house flies were similar for both borates but were dependent on the solvent. Repellency, indicated by a reluctance to feed on test formulations, was not observed, but treatment levels were much lower than those used by Mullens \& Rodriguez (1992).

The objective of our study was to determine whether highly concentrated levels of liquid bo-

This article reports the results of research only. Mention of a proprietary product does not constitute an endorsement or a recommendation for its use by USDA.

1 Department of Entomology and Nematology, Institute of Food and Agricultural Sciences, University of Florida, Gainesville, FL 32611. ric acid and polybor formulations are repellent to adult house flies in nonchoice, choice, and consumption tests. To do this, we formulated borates in $10 \%$ sucrose because of its attractiveness to house fly adults. Results of this study will allow development of optimal liquid bait formulations.

\section{Materials and Methods}

Boric acid and polybor were obtained from U.S. Borax and Chemical, Los Angeles, CA. Solutions of both compounds were formulated in $10 \%$ sucrose in water on a wt/vol basis. The five treatment levels selected for each borate ranged from the highest level used in our previous studies (Hogsette \& Koehler 1992) to near saturation. For boric acid and polybor these were $0.5,1.38$, $2.25,3.13$, and $4.0 \%$ and $1.0,3.0,5.0,7.0$, and $9.0 \%$, respectively. Solutions of $10 \%$ sucrose in water were used during each test as untreated controls. Four cages (replications) of flies ( $n=35$ per replication) exposed to each of the selected borate treatment levels or to $10 \%$ sucrose (control) were used for each test. Unless otherwise stated, the standard exposure period was $24 \mathrm{~h}$.

Adult 3- to 5-d-old house flies (mixed sex) from the USDA Gainesville multiresistant colony were used for all tests. Flies were chilled in a walk-in cooler at $\approx 1^{\circ} \mathrm{C}$ for $<10 \mathrm{~min}$ to facilitate sorting and counting and, unless otherwise stated, were allowed to acclimate in the treatment room $\left(24^{\circ} \mathrm{C}, 65 \% \mathrm{RH}\right)$ for a minimum of $2 \mathrm{~h}$ with a water source before each test.

Intensity of overhead lights was reduced before placement of treatments. However, once treatments were in place, overhead lights were illuminated until the end of the test. Except for 


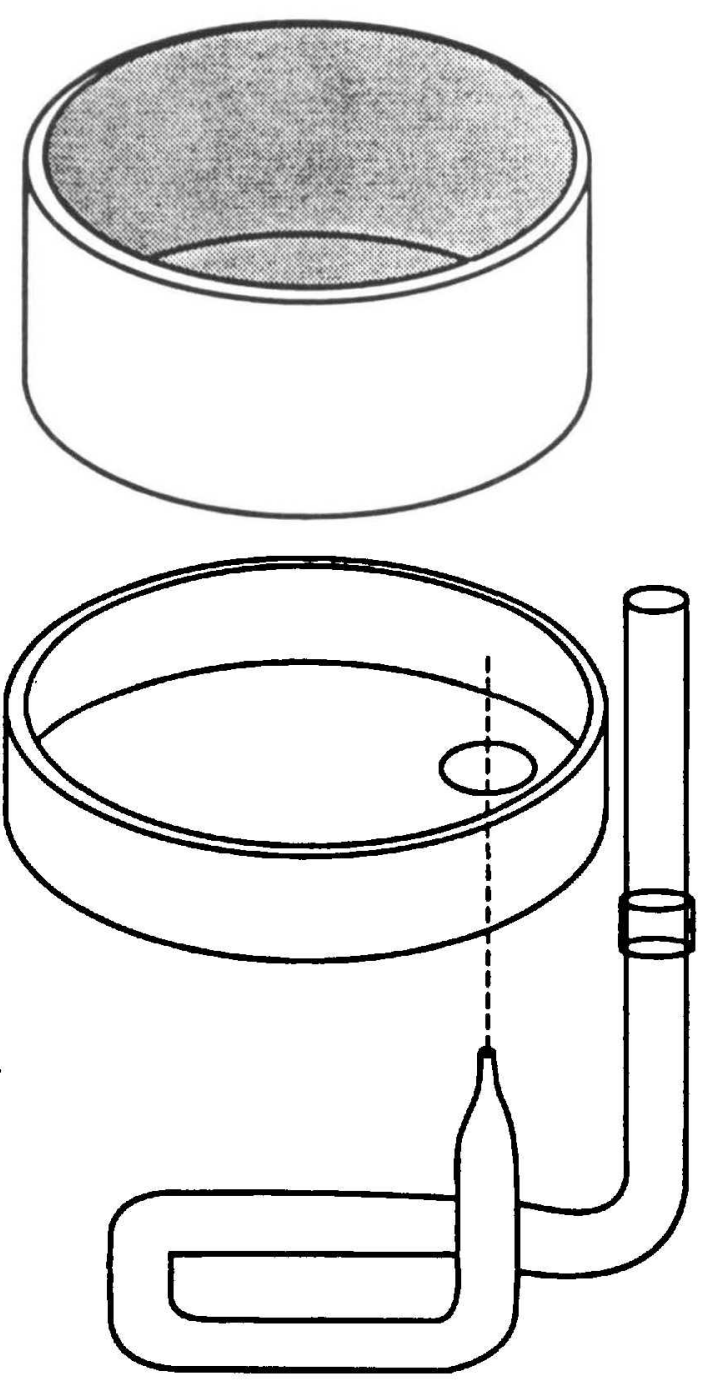

Fig. 1. Modified J-shaped 10-ml pipettes used in conjunction with disposable cages for consumption tests.

consumption tests, mortality was recorded $3,6,9$, and $24 \mathrm{~h}$ after treatments were introduced. The criterion for death was complete cessation of movement. At the end of each test, all flies were killed, and total flies per container was recorded.

Nonchoice Tests. All five treatment levels of both borates were used to check for signs of repellency, as indicated by increases in $\mathrm{LT}_{50} \mathrm{val}$ ues at the higher borate levels. Treatments were administered in scintillation vials $(20 \mathrm{ml})$ fitted with a cotton wick as described in Hogsette \& Koehler (1992). Dry food (powdered milk, granulated sugar, powdered egg yolk; 6:6:1) was provided ad libitum in scintillation vial caps.

Disposable test cages $(\approx 3.4-\mathrm{cm}$ height and 7.6-cm diameter) were made from 0.5-pint (236.6 $\mathrm{ml}$ ) paper cans (Fonda Group, Union, NJ) by removing the bottoms and replacing them with disks of standard aluminum window screen. Cages were oriented with screened sides up (i.e., lids were on the bottom).

A clean paper-can lid was used to introduce treatments. One scintillation vial containing a boric acid or polybor formulation was placed horizontally in the lid along with a scintillation vial cap containing dry food. The screened portion of a test cage, with flies, was lifted from its lid and placed on the clean lid containing the treatment vial and food. This technique allowed us to begin the experiment with $100 \%$ live flies because any dead or dying flies were left behind on the old lids. Escapees totaled $<1 \%$.

During mortality counts, vials and vial caps were moved carefully with a piece of wire inserted through the screen so that no dead flies would be overlooked.

Choice Tests. Low and high treatment levels of boric acid $(0.5 \%$ and $4.0 \%)$ or polybor $(3.0 \%$ and $9.0 \%$ ) in $10 \%$ sucrose individually paired with $10 \%$ sucrose (untreated) were offered freechoice to flies to test for repellency. Tests were performed in hexahedral, wide-mouth, clear plastic jars (1.9-liter) with screw-on lids $(\approx 11$ by 12 by $18 \mathrm{~cm}$ high; Jareen, Los Angeles, CA), oriented with the $11-\mathrm{cm}$ side down. The $11-\mathrm{cm}$ side was grooved, which prevented treatment vials from rolling inside the jars. Small holes were made in the sides and bottom with a heated metal probe to facilitate air exchange. Treatments again were administered in scintillation vials $(20 \mathrm{ml})$ fitted with a cotton wick.

Flies were maintained in the jars with water for $6 \mathrm{~h}$ before the treatments were introduced. By lowering the intensity of the overhead lights and placing a low-intensity fluorescent light source near the end of the jars opposite the lids, lids could be removed without flies escaping. Before treatments were introduced, water sources and dead flies were removed from the jars with forceps. Pairs of vials containing treated and untreated $10 \%$ sucrose solutions were placed horizontally in the opposite ends of each jar, perpendicular to the long axis of the jars and with wicks pointing in opposite directions. Positions (front and back) of treated and untreated vials were alternated by replication. Distance between vials was $\approx 13 \mathrm{~cm}$.

During mortality counts, jars were lifted carefully and viewed from below so that dead flies under vials would not be overlooked.

Consumption Tests. Relative consumption of all five treatment levels of both borates was used as an indication of repellency. Treatments were administered in 10-ml glass pipettes bent in a modified J configuration similar to designs used by Dethier (1976) and Lemke et al. (1990). The parallel sides of the $\mathrm{J}$ were bent $90^{\circ}$ at their midpoints so they were parallel to each other and perpendicular to the plane of the rest of the J. The design allowed the short side to be inserted 
Table 1. Responses of house flies in nonchoice tests to increasing levels of boric acid and polybor formulated in $10 \%$ sucrose (24-h mortality, no starve)

\begin{tabular}{|c|c|c|c|c|}
\hline $\begin{array}{c}\text { Treatment, } \\
\%^{a}\end{array}$ & $n$ & $\mathrm{LT}_{\mathbf{5 0}}, \mathrm{h}$ & $95 \% \mathrm{CI}$ & Slope \pm SEM \\
\hline \multicolumn{5}{|l|}{ Boric acid } \\
\hline 0.5 & 124 & $26.45 \mathrm{a}$ & $15.97-156.23$ & $2.54 \pm 0.74$ \\
\hline 1.38 & 128 & $8.27 b$ & $7.42-9.58$ & $3.26 \pm 0.41$ \\
\hline 2.25 & 121 & $5.40 \mathrm{c}$ & $4.56-\quad 6.37$ & $1.95 \pm 0.35$ \\
\hline 3.13 & 114 & $5.43 c$ & 4.80 & $2.67 \pm 0.38$ \\
\hline 4.0 & 121 & $5.23 \mathrm{c}$ & $4.67-\quad 5.83$ & $2.93 \pm 0.37$ \\
\hline \multicolumn{5}{|l|}{ Polybor } \\
\hline 1.0 & 95 & $11.40 \mathrm{a}$ & $9.52-15.82$ & $3.18 \pm 0.56$ \\
\hline 3.0 & 106 & $5.71 b$ & $4.96-6.62$ & $2.41 \pm 0.38$ \\
\hline 5.0 & 122 & $5.75 b$ & $4.94-6.75$ & $2.08 \pm 0.35$ \\
\hline 7.0 & 125 & $7.77 b$ & $6.74-9.54$ & $2.30 \pm 0.36$ \\
\hline 9.0 & 120 & $7.84 b$ & $6.64-10.13$ & $2.00 \pm 0.36$ \\
\hline
\end{tabular}

Means for each treatment followed by the same letter are not significantly different ( $P=0.05$, Tukey's studentized range test [SAS Institute 1985]).

"Weight/volume.

into a hole in the lid (lower surface) of a disposable cage without touching the screen, leaving the long side exposed for the addition of liquids as desired (Fig. 1). Pipettes were calibrated by adding through the long side as much $10 \%$ sucrose solution as possible without causing the meniscus at the tip of the short side to collapse when touched with a wire probe. This position was marked on the long side with a small band of tightly fitting clear plastic tubing. Tuberculin syringes (1 cc) fitted with 21-gauge needles were used to fill pipettes to their calibrated levels.

Flies were maintained in the disposable cages described above with holes precut to accept the pipettes. Food and water were withheld during the 2-h acclimation period before treatments were introduced. To begin a test, the short sides of partially filled pipettes were inserted into holes in cages, and cages were allowed to rest on the horizontal portion of the Js. Pipettes were then brought up to maximum (calibrated) volumes. Pipettes again were brought up to maximum volumes 3,6 , and $9 \mathrm{~h}$ after treatments were introduced, and the added amounts (volume consumed) were recorded for each pipette. Mortality

Table 2. Responses of house flies in choice tests to high and low levels of boric acid and polybor formulated in $10 \%$ sucrose (24-h mortality, no starve)

\begin{tabular}{lcccc}
\hline $\begin{array}{c}\text { Treatment, } \\
\%^{a}\end{array}$ & $n$ & $\mathrm{LT}_{50}, \mathrm{~h}$ & $95 \% \mathrm{CI}$ & Slope \pm SEM \\
\hline $\begin{array}{l}\text { Boric acid } \\
0.5\end{array}$ & 268 & $33.86 \mathrm{a}$ & $25.13-56.49$ & $2.36 \pm 0.39$ \\
4.0 & 296 & $12.75 \mathrm{~b}$ & $11.18-14.86$ & $3.21 \pm 0.33$ \\
$\begin{array}{l}\text { Polybor } \\
3.0\end{array}$ & 159 & 15.40 & $10.80-55.77$ & $2.76 \pm 0.84$ \\
9.0 & 231 & 495.00 & - & $0.91 \pm 0.82$ \\
\hline
\end{tabular}

Means followed by the same letter are not significantly different $(\boldsymbol{P}=0.05$, Tukey's studentized range test [SAS Institute 1985]).

${ }^{a}$ Weight/volume. was recorded at the same time. Borate ingestion was calculated by multiplying 9-h consumption (ml)-by-treatment concentration $(\mathrm{g} / \mathrm{ml})$.

Statistical Procedures. All tests were performed twice using both borates, and pooled data were subjected to probit analysis (SAS Institute 1985) for estimation of $\mathrm{LT}_{50} \mathrm{~s}$. $\mathrm{LT}_{50} \mathrm{~s}$ with overlapping $95 \%$ confidence intervals were considered not significantly different. Cumulative consumption data in a completely randomized design were analyzed with GLM Procedures, and Tukey's studentized range test (SAS Institute 1985) was used for separation of means. Unless otherwise stated, $P=0.05$.

\section{Results and Discussion}

Nonchoice Tests. $\mathrm{LT}_{50} \mathrm{~s}$ for boric acid decreased with increasing treatment levels over a 24-h treatment period (Table 1). However, responses plateaued at $\approx 5 \mathrm{~h}$ at levels of $2.25 \%$ and above, which indicated repellency. $\mathrm{LT}_{50} \mathrm{~s}$ for treatment levels of $2.25 \%$ and above were not significantly different.

$\mathrm{LT}_{50}$ s for polybor decreased from the $1 \%$ to the $3 \%$ treatment level, then increased numerically at higher treatment levels (Table 1). Although responses for treatment levels of $3 \%$ and above were not significantly different, there was only a slight overlap between the $95 \%$ confidence intervals (CI) of the 5\% levels and the 7 and $9 \%$ treatment levels. Thus, there appeared to be some degree of repellency at the higher treatment levels of polybor.

Choice Tests. The $\mathrm{LT}_{50}$ for flies simultaneously exposed to $4 \%$ boric acid and untreated $10 \%$ sucrose was significantly lower $(12.8 \mathrm{~h})$ than the $\mathrm{LT}_{50}$ for flies simultaneously exposed to $0.5 \%$ boric acid and untreated $10 \%$ sucrose $(33.9$ h) (Table 2). Flies given a choice between $4 \%$ boric acid and $10 \%$ sucrose took twice as long to die as flies exposed to $4 \%$ boric acid alone (Table 1). In contrast, flies given a choice between $0.5 \%$ boric acid and $10 \%$ sucrose took only $20 \%$ longer to die than flies exposed to $0.5 \%$ boric acid alone. This suggests a limited degree of repellency at the $4 \%$ boric acid level.

Table 3. Responses by house flies to increasing levels of boric acid formulated in $10 \%$ sucrose (9-h mortality, 2-h starve) and administered in pipettes

\begin{tabular}{cccrc}
\hline $\begin{array}{c}\text { Treatment, } \\
\%^{a}\end{array}$ & $n$ & LT $_{50}$ & \multicolumn{1}{c}{$95 \%$ CI } & Slope \pm SEM \\
\hline 0.50 & 315 & $11.47 \mathrm{ab}$ & $8.82-20.65$ & $1.81 \pm 0.42$ \\
1.38 & 303 & $13.60 \mathrm{a}$ & $10.01-28.67$ & $1.87 \pm 0.44$ \\
2.25 & 336 & $8.00 \mathrm{bc}$ & $6.92-9.91$ & $2.43 \pm 0.39$ \\
3.13 & 305 & $7.37 \mathrm{bc}$ & $6.35-9.09$ & $2.39 \pm 0.40$ \\
4.00 & 355 & $5.88 \mathrm{c}$ & $5.04-7.01$ & $2.03 \pm 0.35$ \\
\hline
\end{tabular}

Means followed by the same letter are not significantly different $(P=0.05$, Tukey's studentized range test [SAS Institute 1985]).

${ }^{a}$ Weight/volume. 
Table 4. Consumption ( $\mathrm{ml}$ ) by house fies of increasing levels of boric acid formulated in $10 \%$ sucrose (9-h mortality, 2-h starve) and administered in pipettes

\begin{tabular}{lccccccc}
\hline \hline \multirow{2}{*}{ Time, $h$} & \multirow{2}{c}{ No. cages } & \multicolumn{5}{c}{ Treatment, \% } \\
\cline { 2 - 7 } & & 0.50 & 1.38 & 2.25 & 3.13 & 4.0 & Control \\
\hline 3 & 8 & 0.0010 & 0.0039 & 0.0190 & 0.0010 & 0.0021 & 0.0079 \\
6 & 8 & 0.0089 & 0.0090 & 0.0227 & 0.0051 & 0.0050 & 0.0146 \\
9 & 8 & 0.0205 & 0.0236 & 0.0259 & 0.0066 & 0.0063 & 0.0180 \\
Rank & & 3 & 2 & 1 & 5 & 6 & 4 \\
Consumption (AI) (mg) ${ }^{b}$ & & 0.103 & 0.326 & 0.583 & 0.207 & 0.252 & - \\
Rank & & 5 & 2 & 1 & 4 & 3 & \\
\hline
\end{tabular}

a Weight/volume.

${ }^{b}$ Nine-hour consumption $x$ dose.

The $\mathrm{LT}_{50}$ for flies simultaneously exposed to $3 \%$ polybor and untreated $10 \%$ sucrose $(15.4 \mathrm{~h})$ was much lower than the $\mathrm{LT}_{50}$ for flies simultaneously exposed to $9 \%$ polybor and untreated $10 \%$ sucrose $(495.0 \mathrm{~h}$ ) (Table 2). Although flies given a choice between $3 \%$ polybor and $10 \%$ sucrose took approximately three times longer to die than flies exposed to $3 \%$ polybor alone (Table 1), flies given a choice between $9 \%$ polybor and $10 \%$ sucrose took $>60$ times longer to die than flies exposed to $9 \%$ polybor alone. At the higher treatment level, flies appeared to be repelled and died at a much slower rate than flies exposed to the $3 \%$ level.

Consumption Tests. As in the nonchoice tests, the $\mathrm{LT}_{50}$ for flies exposed to $4 \%$ boric acid $(5.9 \mathrm{~h})$ in pipettes was significantly lower than the $\mathrm{LT}_{50}$ for flies exposed to $0.5 \%$ boric acid $(11.5 \mathrm{~h}$ ) (Table 3). Likewise, there was no significant difference between the $\mathrm{LT}_{50} 5$ at $2.25 \%$ or above. However, flies consumed more $2.25 \%$ boric acid solution than any other solution offered (Table 4). Average 9-h consumption at the $2.25 \%$ level was $0.0259 \mathrm{ml}$ per fly, which converts to an ingestion of $0.583 \mathrm{mg}$ of boric acid per fly. Consumption increased with concentration up to the $2.25 \%$ level and decreased markedly at higher levels. Flies receiving the control solution and the $0.5,1.38$, and $2.25 \%$ boric acid solutions imbibed at least 3 times more than flies receiving the 3.13 and $4 \%$ solutions.

$\mathrm{LT}_{50} \mathrm{~s}$ for flies exposed to polybor in pipettes decreased numerically from the 1 to $7 \%$ treatment level and then increased numerically at the 9\% level (Table 5). There were no significant differences between treatment level $\mathrm{LT}_{50} \mathrm{~s}$, but the $7 \%$ level $\mathrm{LT}_{50}$ was numerically, the lowest with the steepest slope. Average 9-hr consumption was highest $(0.0256 \mathrm{ml}$ per $f y)$ at the $3 \%$ level and lowest $(0.0081 \mathrm{ml}$ per fly $)$ at the $9 \%$ level (Table 6). However, actual ingestion of polybor was highest (1.197 $\mathrm{mg}$ per fly) at the $7 \%$ level and lowest ( $0.087 \mathrm{mg}$ per fly) at the $1 \%$ level. As treatment levels increased from 3 to $7 \%$, consumption decreased although ingestion of active ingredient increased. Above the $7 \%$ level, this relationship ceased to exist.
Per-fly consumption over the 9-h test period compared favorably with data of Lemke et al. (1990), if their data are divided by 8 to yield per-fly consumption per pipette values and then converted from 24-h to 9-h values. We did not check for evaporation effects, but values should be minimal and less than those of Lemke et al. (1990) because the duration of our test was only $9 \mathrm{~h}$.

Results of the nonchoice tests suggest that limited repellency exists at levels $>1.38 \%$ for boric acid and at levels $>1 \%$ for polybor (Table 1). Similar $\mathrm{LT}_{50} \mathrm{~s}$ at lower treatment levels and disparate $\mathrm{LT}_{50} \mathrm{~s}$ at higher treatment levels in nonchoice and choice tests indicate that repellency may be more pronounced at the higher treatment levels (Table 2).

Results from consumption tests indicate that boric acid repellency pullulated at levels $>2.25 \%$ (Table 4 ), as reflected by a four-fold decrease in consumption and a concomitant reduction in ingestion of active ingredient at higher levels. Because there was a significant difference between $\mathrm{LT}_{50} \mathrm{~s}$ at levels of 2.25 and $1.38 \%$, $2.25 \%$ boric acid in $10 \%$ sucrose was chosen as the optimal treatment level. Consumption of polybor solutions peaked at the $3 \%$ level and decreased as treatment levels increased (Table 6). However, ingestion of active ingredient increased at a decreasing rate, then decreased sharply after peaking at the $7 \%$ level. Because

Table 5. Responses by house flies to increasing levels of polybor formulated in $10 \%$ sucrose (9-h mortality, $2 \cdot \mathrm{h}$ starve) and administered in pipettes

\begin{tabular}{ccccc}
\hline $\begin{array}{c}\text { Treatment, } \\
\%^{a}\end{array}$ & $n$ & LT $_{\mathbf{5 0}}$ & $95 \% \mathrm{CI}$ & Slope \pm SEM \\
\hline 1 & 558 & 334.23 & - & $0.72 \pm 0.38$ \\
3 & 546 & $31.45 \mathrm{a}$ & $17.53-176.55$ & $1.37 \pm 0.35$ \\
5 & 510 & $21.38 \mathrm{a}$ & $14.50-52.03$ & $1.84 \pm 0.39$ \\
7 & 486 & $20.26 \mathrm{a}$ & $14.30-43.82$ & $2.22 \pm 0.45$ \\
9 & 558 & $30.54 \mathrm{a}$ & $18.27-119.53$ & $1.90 \pm 0.45$ \\
\hline
\end{tabular}

Means followed by the same letter are not significantly different ( $P=0.05$, Tukey's studentized range test [SAS Institute 1985]).

a Weight/volume. 
Table 6. Consumption $(\mathrm{ml})$ by house flies of increasing levels of polybor formulated in $10 \%$ sucrose (9-h mortality, 2-h starve) and administered in pipettes

\begin{tabular}{lccccccc}
\hline \hline \multirow{2}{*}{ Time, h } & \multirow{2}{*}{ No. cages } & \multicolumn{5}{c}{ Treatment, \% } \\
\cline { 3 - 7 } & & 1.0 & 3.0 & 5.0 & 7.0 & 9.0 & Control \\
\hline 3 & 8 & 0.0024 & 0.0036 & 0.0029 & 0.0051 & 0.0018 & 0.0024 \\
6 & 8 & 0.0034 & 0.0047 & 0.0060 & 0.0074 & 0.0038 & 0.0073 \\
9 & 8 & 0.0087 & 0.0256 & 0.0220 & 0.0171 & 0.0081 & 0.0132 \\
Rank & & 5 & 1 & 2 & 3 & 6 & 4 \\
Consumption (AI) (mg) ${ }^{b}$ & & 0.087 & 0.767 & 1.099 & 1.197 & 0.730 & - \\
Rank & & 5 & 3 & 2 & 1 & 4 & \\
\hline
\end{tabular}

a Weight/volume.

"Nine-hour consumption $x$ dose.

there was no significant difference between $\mathrm{LT}_{50} \mathrm{~s}$ at levels of 3,5 , and $7 \%, 3 \%$ polybor in $10 \%$ sucrose was chosen as the optimal treatment level.

House fly repellency to dry sugar-base formulations of polybor at levels $>2 \%$ was first reported by Mullens \& Rodriguez (1992). Repellency of boric acid and polybor bait formulations to German cockroaches, Blattella germanica L., also was reported by Strong et al. (1993). However, no repellency to the aqueous solutions was detected.

It is interesting to note the relative amounts of boric acid and polybor necessary to elicit repellency. Maximum boric acid ingestion occurred at the $2.25 \%$ level (Table 4 ), the point at which liquid consumption peaked. Polybor ingestion peaked at the $7 \%$ level (Table 6), but liquid consumption peaked at the $3 \%$ level. Thus, repellency was effected by treatment levels $>2.25 \%$ boric acid ( $0.583 \mathrm{mg}$ ingested) and $>3 \%$ polybor (0.767 $\mathrm{mg}$ ingested). These levels correspond to $>0.102$ and $>0.161 \mathrm{mg}$ of ingested boron, respectively (formula weights: boric acid $\approx 62$, polybor $\approx 412$ ). Our results are supported by those of Hogsette \& Koehler (1992) who found the relative toxicities of boric acid and polybor to be numerically similar in the same solvents.

\section{Acknowledgments}

We thank G. Langley and F. Washington (USDAARS, Gainesville, FL) for their technical assistance in this study. This is Florida Agricultural Experiment Station Journal Series R-03177.

\section{References Cited}

Bishopp, F. C. 1939. Housefly control. USDA Leaflet no. 182. USDA, Washington, DC.

Dethier, V. G. 1976. The hungry fly: a physiological study of the behavior associated with feeding. Harvard University Press, Cambridge, MA.

Hogsette, J. A. \& P. G. Koehler. 1992. Comparative toxicity of aqueous solutions of boric acid and polybor 3 to house Hies (Diptera: Muscidae). J. Econ. Entomol. 85: 1209-1212.

Langford, G. S., W. T. Johnson \& W. C. Harding. 1954. Bait studies for fly control. J. Econ. Entomol. 47: 438-441.

Lemke, L. A., P. G. Koehler \& R. S. Patterson. 1990. Laboratory method for measuring the attractiveness of pheromones to adult Musca domestica (Diptera: Muscidae). J. Med. Entomol. 27: 1062-1064.

McGovran, E. R. \& P. G. Piquett. 1945 . Toxicity of benzene hexachloride to house fly larvae. J. Econ. Entomol. 38: 719.

Midgley, A. R., W. O. Mueller \& D. E. Dunklee. 1943. Borax and boric acid for control of flies in manure. J. Am. Soc. Agron. 35: 779-785.

Mullens, B. A. \& J. L. Rodriguez. 1992. Effects of disodium octaborate tetrahydrate on survival, behavior, and egg viability of adult muscoid flies (Diptera: Muscidae). J. Econ. Entomol. 85: 137143.

SAS Institute. 1985. SAS user's guide: statistics. SAS Institute, Cary, NC.

Strong, C. A., P. G. Koehler \& R. S. Patterson. 1993. Oral toxicity and repellency of borates to German cockroaches (Dictyoptera: Blattellidae). J. Econ. Entomol. 86: 1458-1463.

Received for publication 21 May 1993; accepted 16 March 1994. 